\title{
Neglected zoonotic agents in cattle abortion: tackling the difficult to grow bacteria
}

Sara Vidal ${ }^{1,2}$, Kristel Kegler ${ }^{3}$, Gilbert Greub ${ }^{4}$, Sebastien Aeby ${ }^{4}$, Nicole Borel ${ }^{5}$, Mark P. Dagleish ${ }^{6}$, Horst Posthaus ${ }^{3}$, Vincent Perreten ${ }^{1}$ and Sabrina Rodriguez-Campos ${ }^{{ }^{*}}$ (1)

\begin{abstract}
Background: Coxiella burnetii, Chlamydia abortus and Leptospira spp. are difficult to grow bacteria that play a role in bovine abortion, but their diagnosis is hampered by their obligate intracellular lifestyle (C. burnetii, C. abortus) or their lability (Leptospira spp.). Their importance is based on the contagious spread in food-producing animals, but also as zoonotic agents. In Switzerland, first-line routine bacteriological diagnostics in cattle abortions is regulated by national law and includes only basic screening by staining for $C$. burnetii due to the high costs associated with extended spectrum analysis. The aim of this study was to assess the true occurrence of these zoonotic pathogens in 249 cases of bovine abortion in Switzerland by serology (ELISA for anti-C. burnetii and C. abortus antibodies and microscopic agglutination test for anti-Leptospira spp. antibodies), molecular methods (real-time PCR and sequencing of PCR products of Chlamydiales-positive cases), Stamp's modification of the Ziehl-Neelsen (mod-ZN) stain and, upon availability of material, by histology and immunohistochemistry (IHC).
\end{abstract}

Results: After seroanalysis the prevalence was $15.9 \%$ for C. burnetii, 38.5\% for C. abortus and $21.4 \%$ for Leptospira spp. By real-time PCR $12.1 \%$ and $16.9 \%$ of the cases were positive for C. burnetii and Chlamydiales, respectively, but only $2.4 \%$ were positive for C. burnetii or Chlamydiales by mod-ZN stain. Sequencing of PCR products of Chlamydiales-positive cases revealed C. abortus in 10\% of cases and the presence of a mix of Chlamydiales-related bacteria in 5.2\% of cases. Pathogenic Leptospira spp. were detected in $5.6 \%$ of cases. Inflammatory lesions were present histologically in all available samples which were real-time PCR-positive for Chlamydiales and Leptospira spp. One of 12 real-time PCR-positive cases for C. burnetii was devoid of histological lesions. None of the pathogens could be detected by $\mathrm{IHC}$.

Conclusion: Molecular detection by real-time PCR complemented by histopathological analysis is recommended to improve definitive diagnosis of bovine abortion cases and determine a more accurate prevalence of these zoonotic pathogens.

Keywords: Coxiella burnetii, Chlamydiales, Leptospira spp., Bovine abortion, Zoonosis

\section{Background}

Abortion in dairy cattle is one of the major causes of economic loss in the livestock industry [1] and three of the bacterial agents that are implicated in bovine abortion during mid- to late-gestation are the difficult to grow: Coxiella burnetii, Chlamydia abortus and pathogenic

\footnotetext{
* Correspondence: sabrina.rodriguez@vetsuisse.unibe.ch

'Institute of Veterinary Bacteriology, Vetsuisse Faculty, University of Bern,

Laenggassstrasse 122, CH-3012 Bern, Switzerland

Full list of author information is available at the end of the article
}

Leptospira spp. Their importance is based on not only in the economic loss in animal production but also in their zoonotic risk [2-4].

C. abortus and C. burnetii are obligate intracellular Gram-negative bacteria. C. abortus, the causative agent of ovine enzootic abortion, may also lead to reproductive disorders in large ruminants $[2,5]$ and is known to cause spontaneous abortion in pregnant women $[5,6]$. Other members of the families Chlamydiaceae, Parachlamydiaceae and Waddliaceae have also been found to play a 
possible role in abortion in ruminants as well as in humans [7-11]. C. burnetii has a wide host range, including domestic and wild animals. Infection in most animals is subclinical or presents with non-specific clinical signs, whereas ruminants, the main reservoir of infection, may present with late abortion and stillbirths; moreover, C. burnetii might be associated with metritis and infertility in cattle $[3,12-18]$. Human infection with $C$. burnetii is known as $\mathrm{Q}$ fever and can lead to miscarriage in women [19-21]. Leptospirosis is caused by Gram-negative, pathogenic spirochetes of the genus Leptospira that is divided in more than 250 pathogenic serovars worldwide, which are classified into 25 serogroups on the basis of their serological phenotype. In cattle, leptospirosis is mainly associated with reproductive problems including infertility, low conception rate, abortion, stillbirths and weak offspring [22-24]. Cattle are considered to be the maintenance host of serovar Hardjo resulting in a high degree of subclinical infections [25]. Human leptospirosis occurs worldwide, is transmitted via direct or indirect contact with urine from infected animals and is due mostly to recreational and occupational activities [26-28]. Numerous outbreaks of leptospirosis worldwide have been also associated with heavy rainfall and flooding [29, 30]. Abortion in women due to leptospirosis may occur if infection takes place during pregnancy $[31,32]$.

Given the numerous possible etiologies of abortion in ruminants and the high cost of definitive diagnosis, a finance-limited investigation is performed usually, and the causative agent often remains undetermined [33]. Of the three cattle abortifacient pathogens discussed, only investigation of C. burnetii is legally regulated in Switzerland requiring Stamp's modification of the Ziehl-Neelsen $(\bmod -\mathrm{ZN})$ stain [34] of tissue smears [Ordinance on Epizootic Diseases (TSV) SR.916.401; Article 129].

According to the epizootics database of the Swiss Federal Food Safety and Veterinary Office (InfoSM www.infosm.blv.admin.ch, consulted on 02/08/2017), 676 cases of coxiellosis in cattle were reported from 2006 to 2016. Although pathogenic Leptospira spp. and $C$. abortus are not included in routine bovine abortion diagnostics and, moreover, Leptospira interrogans serovar Hardjo is exempt from mandatory notification in cattle, 43 cases of leptospirosis and 23 cases of chlamydiosis in cattle were reported in the same time frame.

In this study, the recommended mod-ZN method was complemented with serology, molecular methods, histology and immunohistochemistry to determine the degree of underestimation of the three abortifacient pathogens $C$. burnetii, C. abortus and pathogenic Leptospira spp. in bovine abortion in Switzerland.

\section{Methods}

\section{Collection of samples}

Samples from 249 cases of bovine abortion from different cantons of Switzerland were collected from October 2012 to October 2015 [Bern $(n=213)$, Vaud $(n=7)$, Fribourg $(n=6)$, Jura $(n=6)$, Solothurn $(n=6)$, Aargau $(n=2)$, Basel-Land $(n=2)$, Neuchâtel $(n=2)$, Valais $(n=$ $2)$, Zurich $(n=2)$ and Luzern $(n=1)]$. The 249 cases comprised 242 placentas, 57 fetal abomasal contents and 182 maternal sera submitted for routine abortion diagnostics. Placenta from a healthy calf was included as a negative control.

\section{Stamp's modification of the Ziehl-Neelsen stain}

Smears of placentas, abomasal contents $(n=299)$ and the negative control placenta were subjected to modZN staining [32] and examined by light microscopy. Chlamydia-positive placental tissue was included as positive control in every stain. The sample was considered positive for Chlamydiales and/or C. burnetii when intracytoplasmic red-stained coccobacilli appeared in clumps against a blue background. The technique does not allow a differentiation between Chlamydiales and C. burnetii.

\section{Serological studies}

The 182 maternal sera were tested for antibodies against $C$. burnetii and $C$. abortus using the commercial $\mathrm{CHEKIT}^{\circ} \mathrm{Q}$ fever antibody ELISA Test Kit and CHEKIT $^{\circ}$ C. abortus Antibody Test Kit (IDEXX, Liebefeld-Bern, Switzerland) according to the manufacturer's instructions. The results were expressed as $\mathrm{S} / \mathrm{P}$ values and derived from the ratio between optical density (OD) of the sample (S) and the OD of positive control $(\mathrm{P})$ included in the kits. IDEXX state an $\mathrm{S} / \mathrm{P}$ $\geq 40 \%$ is considered positive, an $\mathrm{S} / \mathrm{P}<30 \%$ is considered negative, and $\mathrm{S} / \mathrm{P}$ values between these are considered suspect positive.

The serological detection of antibodies against Leptospira spp. was performed by microscopic agglutination test (MAT) (Manual of Diagnostic Tests and Vaccines for Terrestrial Animals of the Ordinance of Epizootic Diseases [22]). Twelve serovars were included in the test panel: Australis, Autumnalis, Ballum, Bataviae, Bratislava, Canicola, Grippotyphosa, Hardjo, Icterohaemorrhagiae, Pomona, Sejroe and Tarassovi (Additional file 1: Table S1). Sera were screened initially for agglutination at a dilution of $1: 100$ in sterile $0.85 \% \mathrm{NaCl}$. Reactive sera were titrated in two-fold serial dilutions to determine the end-point titer defined as the dilution at which at least 50\% agglutination occurs. In every serological analysis negative and positive control sera were included as controls. 


\section{DNA extraction and molecular studies}

For the extraction of total genomic DNA $2 \mathrm{~g}$ of placenta or $2 \mathrm{~mL}$ of fetal abomasal content were suspended in $5 \mathrm{~mL} 0.85 \% \mathrm{NaCl}$ in an IKA ${ }^{\oplus}$ DT-20 tube [35] and homogenized twice for $30 \mathrm{~s}$ at $6000 \mathrm{rpm}$, using the IKA ULTRATURRAX $^{\oplus}$ tube drive. Subsequently, $500 \mu \mathrm{L}$ of the homogenates were used for DNA extraction using QIAamp Mini Kit (Qiagen, Hombrechtikon, Switzerland). Fluorometric quantification of DNA was performed by Quantus ${ }^{\text {TM }}$ Fluorometer (Promega, Dübendorf, Switzerland).

Real-time PCR targeting the IS1111 of C. burnetii was performed according to Howe et al. [36]: IS1111F801: 5' AATTTCATCGTTCCCGGCAG 3'; IS1111R901: 5' GCCGCGTTTACTAATCCCCA 3'; probe IS1111-p822S-MGB: 5' 6FAM-TGTCGGCGTTTATTGG -MGBNFQ 3'. PCR was performed in a total volume of $25 \mu \mathrm{L}, 1 \mathrm{X}$ final concentration of TaqMan Universal PCR Master Mix (Applied Biosystems, Foster City, CA, USA), $1 \mu \mathrm{M}$ of each primer, $80 \mathrm{nM}$ of the probe, $0.5 \mathrm{X}$ of internal positive control (IPC) Template, 0.5X IPC Mix and $2.5 \mu \mathrm{L}$ of the template. The following conditions were applied: $94{ }^{\circ} \mathrm{C}$ for $2 \mathrm{~min}, 40$ cycles of $94{ }^{\circ} \mathrm{C}$ for $15 \mathrm{~s}$ and $60{ }^{\circ} \mathrm{C}$ for $30 \mathrm{~s}$. Amplification was performed in duplicate on the TaqMan 7500 Fast Real-time PCR System (Applied Biosystems, Zug, Switzerland). As positive and negative controls C. burnetii DNA and water were used, respectively. Samples were considered positive when showing an exponential amplification curve up to cycle 39 in both replicates.

A pan-Chlamydiales real-time PCR targeting the Chlamydiales $16 \mathrm{~S}$ rDNA was performed according to Lienard et al. [37]: panCh16F2: 5' CCGCCAACACTGG GACT 3'; panCh16R2: 5' GGAGTTAGCCGGTGCTTC TTTAC 3'; probe panCh16S: 5' 6FAM-CTACGGGAGGCTGCAGTCGAGAATC-BHQ1 3'. PCR assays were performed in $20 \mu \mathrm{L}$, with iTaq Supermix with ROX (Bio-Rad, Reinach, Switzerland), $0.1 \mu \mathrm{M}$ concentrations of each primer (Eurogentec, Seraing, Belgium), a $0.1 \mu \mathrm{M}$ concentration of probe (Eurogentec), molecularbiology-grade water (Sigma-Aldrich, Buchs, Switzerland) and $5 \mu \mathrm{L}$ of DNA sample. The cycling conditions were $3 \mathrm{~min}$ at $95{ }^{\circ} \mathrm{C}$, followed by 50 cycles of $15 \mathrm{~s}$ at $95^{\circ} \mathrm{C}, 15 \mathrm{~s}$ at $67{ }^{\circ} \mathrm{C}$ and $15 \mathrm{~s}$ at $72{ }^{\circ} \mathrm{C}$. Samples were tested in duplicate using a StepOnePlus ${ }^{\mathrm{Tm}}$ Real-time PCR System (Applied Biosystems, Foster City, CA, USA). As positive and negative controls $C$. abortus DNA and water were used, respectively. Samples were considered positive when showing an exponential amplification curve up to cycle 40 in both replicates. Samples exhibiting a cycle threshold $(\mathrm{Ct})$ of $\leq 35$ cycles were sequenced using specifically designed internal sequencing primers as described by Lienard et al. [37]. Obtained sequences were edited and analyzed by BLAST on the NCBI website (http:// www.ncbi.nlm.nih.gov).
Real-time PCR targeting the lipL32 gene of Leptospira spp. was performed using primers and probe described by Villumsen et al. [38]: LipL32-F: 5' AGAGGTCTTTACAGAATTTCTTTCACTACCT 3'; LipL32-R: 5' TGGGAAAAGCAGACCAACAGA 3'; probe LipL32-P: 5 ' 6FAM-AAGTGAAAGGATCTTTCGTTGC-MGBN FQ 3'. PCR was performed in a total volume of $25 \mu \mathrm{L}$, $1 \mathrm{X}$ final concentration of TaqMan Universal PCR Master Mix, $1 \mu \mathrm{M}$ of each primer, $80 \mathrm{nM}$ of the probe, $0.5 \mathrm{X}$ of IPC Template and 0.5X IPC Mix and $2.5 \mu \mathrm{L}$ of the template. The following conditions were applied: $94{ }^{\circ} \mathrm{C}$ for $2 \mathrm{~min}, 45$ cycles of $94{ }^{\circ} \mathrm{C}$ for $15 \mathrm{~s}$ and $60{ }^{\circ} \mathrm{C}$ for $30 \mathrm{~s}$ using the TaqMan 7500 Fast Real-time PCR System. DNA of Leptospira spp. serovar Icterohaemorrhagiae strain RGA and water were used as positive and negative controls, respectively. Samples were considered positive when showing an exponential amplification curve up to cycle 40 in both replicates.

\section{Histopathology}

To assess the significance of the molecular analysis, all cases with real-time PCR-positive results were examined histopathologically and by IHC $(n=32)$ when the placental tissue was available and was not severely autolytic. Selected samples of placenta were fixed in buffered formalin (10\%), processed routinely through graded alcohols and embedded in paraffin-wax. Sections $(4 \mu \mathrm{m})$ were mounted on Thermo Scientific ${ }^{\mathrm{TM}}$ SuperFrost Plus $\odot$ (Braunschweig, Germany) slides and stained with hematoxylin and eosin (HE) for histological evaluation.

\section{Antibodies}

For immunohistochemistry, mouse monoclonal antiCoxiella burnetii antibody (clone 3.13, Squarix $\mathrm{GmbH}$, Marl, Germany) diluted 1:500 in Tris-buffered saline (TBS), an anti-Chlamydiaceae-specific antibody directed against the chlamydial lipopolysaccharide (LPS, Clone ACI-P, Progen, Heidelberg, Germany) diluted 1:200 in antibody diluent (Glostrup, Denmark) and a rabbit polyclonal anti-LipL32 antibody (kindly provided by Dr. Jarlath Nally) diluted 1:1000 in phosphate-buffered saline (PBS) for detection of pathogenic Leptospira spp. were used.

\section{Immunohistochemistry (IHC)}

All real-time PCR-positive cases for C. burnetii $(n=13)$, Chlamydiales $(n=14)$ and Leptospira spp. $(n=5)$ were subjected to immunohistochemistry when tissue was available and not autolytic.

Briefly, for all three antibodies $4 \mu \mathrm{m}$ thick sections were deparaffinized and rehydrated through graded alcohols.

For $C$. burnetii, sections were immersed in $3 \% \mathrm{H}_{2} \mathrm{O}_{2}$ in methanol $(\mathrm{v} / \mathrm{v})$ for $20 \mathrm{~min}$ to quench endogenous 
tissue peroxidases. Non-specific antibody binding was blocked with 25\% normal goat serum (NGS, Vector Laboratories, Peterborough, UK) in TBS for $30 \mathrm{~min}$ and incubated with the primary antibody overnight at $4{ }^{\circ} \mathrm{C}$. Visualization of the bound anti-C. burnetii primary antibody was by EnVision Kit (goat anti-mouse horseradish peroxidase conjugate, DakoCytomation, Ely, UK) according to the manufacturer's instructions followed by addition of the chromogen 3-amino, 9-ethyl-carbazole (AEC, Vector Laboratories, Peterborough, United Kingdom) for $10 \mathrm{~min}$.

Chlamydiaceae immunohistochemistry was performed as described by Borel et al. [39] using the detection kit Dako ChemMate (Dako, Glostrup, Denmark).

Immunohistochemistry for pathogenic Leptospira spp. was performed using the avidin-biotin-peroxidase complex $(\mathrm{ABC})$ method. Sections were treated with 0.5\% $\mathrm{H}_{2} \mathrm{O}_{2}$ in methanol (v/v) for 30 min to block endogenous peroxidase, heated in sodium-citrate buffer for $30 \mathrm{~min}$ in the microwave for antigen retrieval, incubated with $20 \%$ goat serum for $30 \mathrm{~min}$, then incubated with the respective primary antibody overnight at $4{ }^{\circ} \mathrm{C}$. Biotinylated goat-anti-rabbit IgG (BA-1000) diluted 1:200 in PBS (Vector Laboratories, Burlingame, CA, USA) was used as secondary antibody with incubation time of $60 \mathrm{~min}$. Colour development was with 3,3'-diaminobenzidine tetrahydrochloride (DAB) with $\mathrm{H}_{2} \mathrm{O}_{2}(0.03 \%$, $\mathrm{pH}$ 7.2) for 5 min.

Sections immunolabeled with the respective primary antibodies against Chlamydiaceae, C. burnetii and pathogenic Leptospira spp. were all counterstained with hematoxylin prior to mounting in an appropriate mountant.

Four qPCR-negative cases for all three agents were included as negative controls. For C. burnetii and pathogenic Leptospira spp., primary antibodies were substituted with an isotype matched normal mouse IgG antibody or normal rabbit IgG (1:3000; R4505; Sigma Aldrich, Taufkirchen, Germany), respectively, as method negative control preparations.

Sections of intestinal tissue from gnotobiotic piglets experimentally infected with porcine Chlamydia suis strain S45/6, C. burnetii-positive sheep and human placentas and hamster kidney infected with $L$. interrogans serovar Hardjo JB191 were included as positive controls.

\section{Statistical analysis}

We calculated the degree of agreement between the serological and the molecular tests for C. burnetii, $C$. abortus and Leptospira spp. carried out in 182 cases using Cohen's kappa ( $\mathrm{k}$ ) coefficient with $95 \%$ of CIs with the online software GraphPad (http://graphpad.com/ quickcalcs/kappa2). Standard cutoffs were used to define poor $(\kappa<0.40)$, fair $(\kappa=0.41-0.60)$, good $(\kappa=0.61-0.80)$ and very good agreement $(\kappa \geq 0.80)$. The techniques that do not allow for detection of a specific pathogen or yielded only negative results were not included in the comparison.

\section{Results}

Stamp's modification of the Ziehl-Neelsen stain

Of the 299 tissue smears, 10 placental smears and two of abomasal contents were positive as denoted by the presence of red intracytoplasmic organisms consistent with coccobacilli. One of the positive placenta and abomasal content samples were from the same case (Additional file 2: Table S2).

\section{Detection by serological analysis}

Of the 182 sera tested, 29 (15.9\%) were positive for $C$. burnetii and two (1.1\%) were suspect positive. Chlamydial antibodies were detected in $70(38.5 \%)$ of the 182 sera and $23(12.6 \%)$ sera were suspect positive. The prevalence of antibodies against Leptospira spp. was $39 / 182$ (21.4\%), with 21 (11.5\%) sera being positive for at least two serovars. Serovar Hardjo was the most frequent (31/39) followed by serovar Sejroe (14/39). Yet, 12 sera were positive for both serovars with 10 sera showing a higher titer for Hardjo and, hence, indicating that the latter is the causative serovar. Six cases were positive for serovar Australis (Table 1).

\section{Detection by molecular analysis}

Real-time PCR detection of C. burnetii was positive in 28/242 (11.6\%) placenta and 7/57 (12.3\%) abomasal content samples. The pan-Chlamydiales real-time PCR was positive for $41 / 242$ placenta (16.9\%) and 2/57 (3.5\%) abomasal content samples. The results after amplicon sequencing of positive samples with a $\mathrm{Ct} \leq 35$ are summarized in Table 2. C. abortus was detected in 24 placenta samples and in one abomasal content sample. New Chlamydia-related bacteria were detected in four placenta samples. All four were distantly related to known species but all four could be assigned to the Parachlamydiaceae family since they exhibited $>90 \%$ similarity with at least a member of this clade. The sequencing of the remaining 12 samples was not discriminatory because of superposition of sequences, probably due to the presence of more than one member of the Chlamydiales order in the sample. Real-time PCR for the detection of Leptospira spp. was positive for 14/242 (5.8\%) samples of placenta and 1/57 (1.8\%) samples of abomasal contents. For seven of the samples positive by realtime PCR, serum for analysis by MAT was available and was positive in five cases (serovar Hardjo, $n=4$; serovar Icterohaemorrhagiae, $n=1$ ) and negative in two cases. All the results of the molecular analyses are 
Table 1 Positive samples by microscopic agglutination test for the 12 tested serovars of Leptospira spp.

\begin{tabular}{|c|c|c|c|c|c|c|c|c|c|c|c|c|}
\hline \multirow[t]{2}{*}{ Sample ID } & \multicolumn{12}{|l|}{ Serovar } \\
\hline & $\mathrm{Har}$ & Sej & Aus & Bal & Bra & Aut & Gri & Ict & Pom & Tar & Bat & Can \\
\hline 12 Ue1157 & $1: 400$ & & & & & & $1: 400$ & & & & & \\
\hline 13Ue0703 & 1:400 & & & & & 1:200 & & & & & & \\
\hline 13Ue0920 & $1: 400$ & & $1: 400$ & & & & & & & & & \\
\hline 13Ue1137 & $1: 200$ & & & & & & & & & & & \\
\hline 13Ue1300 & $1: 1600$ & $1: 3200$ & & & & & & & & $1: 100$ & & \\
\hline 13 Ue1475 & $1: 3200$ & & & & & & & & & & & \\
\hline 13Ue1631 & $1: 400$ & & $1: 3200$ & & $1: 3200$ & & & & & & & \\
\hline 13Ue1769 & $1: 3200$ & & & & & & & & & & & \\
\hline $14 \mathrm{~A} 0004$ & $1: 3200$ & & & & & & & & & & & \\
\hline $14 \mathrm{~A} 0027$ & $1: 3200$ & $1: 1600$ & & & & & & & & & & \\
\hline $14 \mathrm{~A} 0032$ & & & $1: 3200$ & & & & & & & & & \\
\hline $14 \mathrm{~A} 0035$ & & & $1: 3200$ & & & & & & & & & \\
\hline 14A0051 & 1:800 & & & & & & & & & & & \\
\hline $14 \mathrm{~A} 0057$ & & 1:200 & & & & & & & & & & \\
\hline $14 \mathrm{~A} 0078$ & $1: 3200$ & & & & & & & & & & & \\
\hline $14 \mathrm{~A} 0088$ & & & $1: 3200$ & & $1: 3200$ & & & & & & & \\
\hline $14 \mathrm{~A} 0090$ & $1: 3200$ & & & & & & & & & & & \\
\hline $15 \mathrm{~A} 0004$ & $1: 1600$ & 1:200 & & & & & & & & & & \\
\hline $15 A 0019$ & 1:800 & & & & & & & & & & & \\
\hline $15 \mathrm{~A} 0060$ & & $1: 400$ & & & & & & & & & & \\
\hline $15 \mathrm{~A} 0063$ & $1: 1600$ & 1:400 & & & & & & & & & & \\
\hline $15 \mathrm{~A} 0082$ & $1: 1600$ & 1:400 & & & & & & & & & & \\
\hline $15 A 0086$ & $1: 1600$ & & & $1: 400$ & & & & & & & & \\
\hline 15A0093 & & & $1: 1600$ & & 1:400 & 1:800 & & & & & & \\
\hline $15 \mathrm{~A} 0103$ & $1: 400$ & & & & & & & & & & & \\
\hline $15 \mathrm{~A} 0107$ & $1: 800$ & 1:100 & & & & & & & & & & \\
\hline $15 \mathrm{~A} 0112$ & $1: 1600$ & 1:200 & & & & & & & & & & \\
\hline $15 \mathrm{~A} 0114$ & 1:800 & $1: 200$ & & & & & & & & & & \\
\hline $15 \mathrm{~A} 0122$ & 1:400 & & & & & & & & & & & \\
\hline $15 \mathrm{~A} 0127$ & $1: 400$ & & & & & & & & & & & \\
\hline $15 \mathrm{~A} 0135$ & 1:400 & & & & & & & & & & & \\
\hline $15 \mathrm{~A} 0137$ & $1: 800$ & & & & & & & & 1:400 & & & \\
\hline $15 \mathrm{~A} 0146$ & 1:800 & 1:100 & & & & & & & & & & \\
\hline $15 \mathrm{~A} 0147$ & & & & $1: 200$ & & & & & & & & \\
\hline $15 A 0149$ & $1: 800$ & $1: 400$ & & & & & & & & & & \\
\hline $15 \mathrm{~A} 0157$ & $1: 400$ & $1: 200$ & & & & & & & & & & \\
\hline $15 A 0162$ & 1:100 & $1: 200$ & & & & & & & & & & \\
\hline $15 \mathrm{~A} 0167$ & $1: 800$ & & & & & & & & & & & \\
\hline $15 \mathrm{~A} 0171$ & & & & $1: 200$ & & & & 1:800 & & & & \\
\hline Total no. & 31 & 14 & 6 & 3 & 3 & 2 & 1 & 1 & 1 & 1 & 0 & 0 \\
\hline
\end{tabular}

Har Hardjo, Sej Sejroe, Aus Australis, Bal Ballum, Bra Bratislava, Aut Autumnalis, Gri Grippotyphosa, Ict Icterohaemorrhagiae, Pom Pomona, Tar Tarassovi, Bat Bataviae, Can Canicola 
Table 2 Sequence results of Chlamydiales samples positive by real-time PCR. Not interpretable: presence of multiple peaks

\begin{tabular}{|c|c|c|c|c|}
\hline Sample ID & Organ & Related microorganism & GenBank accession no. & Similarity \% \\
\hline 12 Ue0622 & Placenta & Not interpretable & - & - \\
\hline 12 Ue1119 & Placenta & Chlamydia abortus & Z49871 & 100 \\
\hline 12 Ue1503 & Placenta & $\begin{array}{l}\text { Uncultured Chlamydiales bacterium } \\
\text { clone HE210023biof }\end{array}$ & JX083111 & 99.3 \\
\hline 12Ue1510 & Placenta & Chlamydia abortus & NR_036834 & 100 \\
\hline 13Ue0490 & Placenta & Chlamydia abortus & Z49871 & 94.7 \\
\hline 13Ue0499 & Placenta & Not interpretable & - & - \\
\hline 13Ue0815 & Placenta & Chlamydiales bacterium cvE71 & JF706724 & 96 \\
\hline 13Ue0857 & Placenta & Chlamydia abortus & Z49871 & 100 \\
\hline 13Ue1009 & Placenta & Chlamydia abortus & Z49871 & 99.3 \\
\hline 13Ue1293 & Placenta & Chlamydia abortus & Z49871 & 100 \\
\hline 13Ue1359 & Placenta & Chlamydia abortus & Z49871 & 100 \\
\hline $14 \mathrm{~A} 0078$ & Placenta & Chlamydia abortus & Z49871 & 98.5 \\
\hline 15A0068 & Placenta & Chlamydia abortus & Z49871 & 90.8 \\
\hline $15 \mathrm{~A} 0076$ & Placenta & Not interpretable & - & - \\
\hline $15 \mathrm{~A} 0078$ & Placenta & Chlamydia abortus & Z49871 & 99.5 \\
\hline $15 A 0079$ & Placenta & Chlamydia abortus & Z49871 & 99.8 \\
\hline $15 \mathrm{~A} 0080$ & Placenta & Chlamydia abortus & Z49871 & 99.5 \\
\hline $15 \mathrm{~A} 0082$ & Placenta & Chlamydia abortus & Z49871 & 96.2 \\
\hline 15A0087 & Placenta & $\begin{array}{l}\text { Uncultured Chlamydiales bacterium } \\
\text { clone P-9 }\end{array}$ & AF364575 & 97 \\
\hline 15A0091 & Placenta & Chlamydia abortus & Z49871 & 92 \\
\hline 15A0092 & Placenta & Chlamydia abortus & Z49871 & 100 \\
\hline 15A0093 & Placenta & Chlamydia abortus & Z49871 & 90.8 \\
\hline 15A0096 & Placenta & Chlamydia abortus & Z49871 & 99.5 \\
\hline 15A0096 & Abomasal content & Chlamydia abortus & Z49871 & 99.5 \\
\hline 15A0099 & Placenta & Not interpretable & - & - \\
\hline 15A0104 & Placenta & Chlamydia abortus & Z49871 & 100 \\
\hline 15A0107 & Placenta & Not interpretable & - & - \\
\hline 15A0111 & Placenta & Chlamydia abortus & Z49871 & 99.5 \\
\hline $15 \mathrm{~A} 0113$ & Placenta & Chlamydia abortus & Z49871 & 100 \\
\hline $15 \mathrm{~A} 0114$ & Placenta & Chlamydia abortus & Z49871 & 99.5 \\
\hline $15 \mathrm{~A} 0117$ & Placenta & Not interpretable & - & - \\
\hline $15 A 0118$ & Placenta & Chlamydia abortus & Z49871 & 96.8 \\
\hline 15A0121 & Placenta & Chlamydia abortus & Z49871 & 98.1 \\
\hline $15 \mathrm{~A} 0122$ & Placenta & Chlamydia abortus & Z49871 & 97.6 \\
\hline $15 \mathrm{~A} 0126$ & Abomasal content & Not interpretable & - & - \\
\hline $15 \mathrm{~A} 0129$ & Placenta & Not interpretable & - & - \\
\hline 15A0137 & Placenta & Not interpretable & - & - \\
\hline $15 \mathrm{~A} 0148$ & Placenta & Not interpretable & - & - \\
\hline 15A0155 & Placenta & Parachlamydia acanthamoebae strain Bn9 & NR_026357 & 90.3 \\
\hline $15 \mathrm{~A} 0160$ & Placenta & Not interpretable & - & - \\
\hline 15A0172 & Placenta & Not interpretable & - & - \\
\hline
\end{tabular}


included in Additional file 2: Table S2 and the percentage of positive placenta and abomasal content samples is summarized in Fig. 1.

To compare serological and molecular techniques we analyzed 182 cases that were processed by ELISA, MAT and PCR (Fig. 2). All three pathogens had more positive results in the serological analyses than in the molecular analysis, with $C$. abortus having the highest seropositivity. Results from samples that were positive by real-time PCR for more than one pathogen are summarized in Table 3.

\section{Histopathology and IHC}

The severity of the placentitis, necrosis, inflammatory cell infiltrate and vasculitis in all real-time PCR-positive cases of C. burnetii, Chlamydiales and Leptospira spp. that were evaluated histologically (when tissue was available and not autolytic) varied greatly and the histological findings are summarized in Table 4.

Regardless of the etiological agent, if necrosis was present in the cotyledon it was multifocal, randomly distributed and affected the chorioallantoic stroma and the villi including the trophoblasts.

Placentitis was present in 12 of 13 samples that were positive for C. burnetii by real-time PCR. Necrosis was present in 11 of 13 cases. Mixed inflammatory infiltrates characterized by neutrophils, macrophages and lymphocytes were present in nine of 13 cases and only three cases were designated as suppurative placentitis. Vasculitis was present in five of 13 cases and characterized by infiltration of neutrophils, macrophages and lymphocytes primarily in the tunicae media and adventitia resulting in mild fibrinoid necrosis only (Fig. 3a). All cases positive for Chlamydiales by real-time PCR had placentitis and necrosis. Mixed inflammatory cell infiltrates were present in 12 of

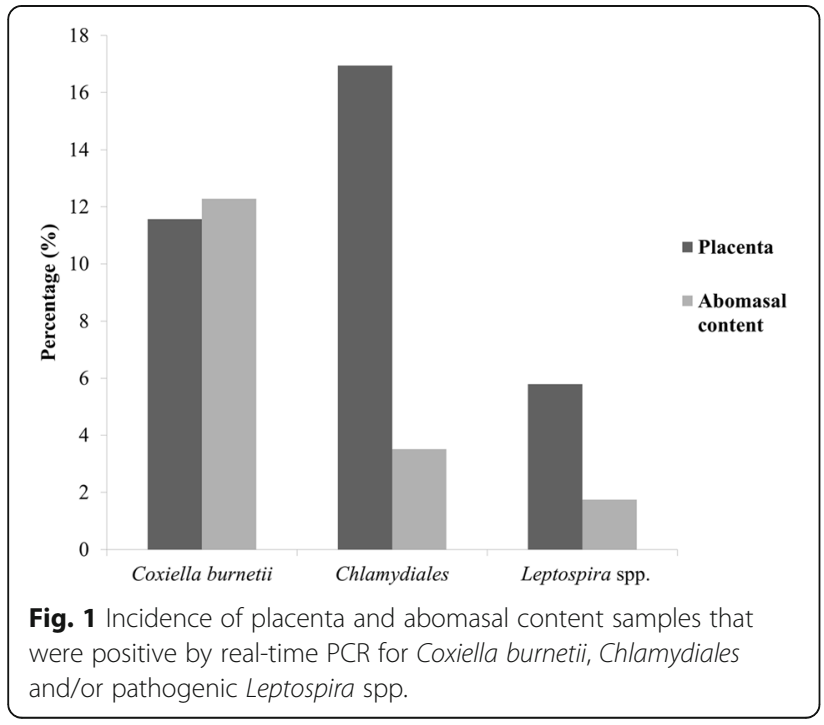

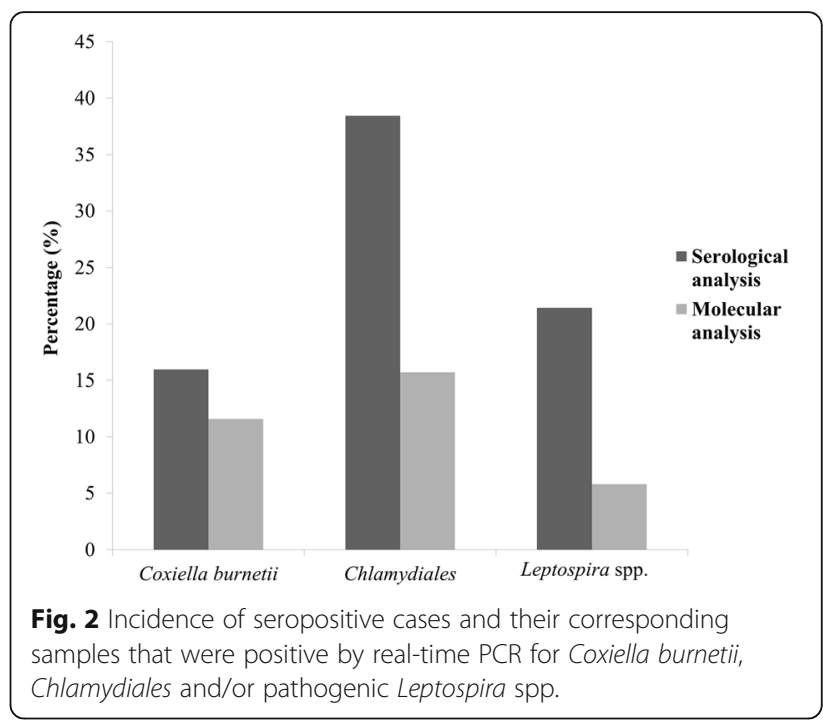

14 cases, only one was designated suppurative and one case was infiltrated by macrophages and lymphocytes (mononuclear) only. Vasculitis was present in seven of the 14 cases (Fig. 3b). Similarly, all cases of Leptospira spp. positive by real-time PCR had placentitis and necrosis (Fig. 3c). Mixed inflammatory cell infiltrates were present in three of five cases, while in two cases the inflammation was comprised of mononuclear leukocytes only. For cases positive for Leptospira spp. by real-time PCR no suppurative placentitis was found and only one case had vasculitis.

Immunohistochemical analysis failed to visualize $C$. burnetii, Chlamydiales and Leptospira spp. in all sections evaluated (Table 4).

\section{Statistical analysis}

The Cohen's kappa coefficient is summarized in Table 5. The degree of agreement between the serological and the molecular diagnostic techniques for C. burnetii, C. abortus and Leptospira spp. was poor with $\mathrm{\kappa}=0.103 \pm 0.086, \mathrm{\kappa}=$ $-0.006 \pm 0.067$ and $\kappa=0.163 \pm 0.074$, respectively.

\section{Discussion}

This study investigated, concomitantly, the prevalence of C. burnetii, C. abortus and pathogenic Leptospira spp. DNA in bovine abortion material and seroconversion in affected dams and highlights the underestimation associated with using a single staining technique. Although detection of any of these pathogens does not equate invariably to causality with respect to bovine abortion, their presence does invariably represent a high zoonotic risk and a possible reservoir of infection for other animals.

The frequency of antibodies specific for C. burnetii in dams was $15.9 \%$, comparable to the reported seroprevalence of $16.7 \%$ in aborting cows in Switzerland by Hässig 
Table 3 Results of six cases of bovine abortion which were positive for more than one pathogen

\begin{tabular}{|c|c|c|c|c|c|c|c|c|c|}
\hline Lab ID & Cox-ELISA & Cab-ELISA & Lep MAT & Lep Serovar & Organ & mod-ZN Cox-Chl & Cox-qPCR & Chl-qPCR & Lep-qPCR \\
\hline \multirow[t]{2}{*}{ 12Ue0622 } & NA & NA & NA & & $A C$ & - & + & - & - \\
\hline & & & & & $P L$ & - & + & + & - \\
\hline 13Ue1009 & + & S & - & & $P L$ & - & + & + & - \\
\hline $14 \mathrm{~A} 0078$ & - & - & + & Har & $P L$ & - & + & + & - \\
\hline $15 A 0087$ & - & S & - & & $P L$ & - & + & + & - \\
\hline 15A0092 & - & S & - & & $P L$ & - & - & + & + \\
\hline 15A0099 & - & - & - & & $P L$ & - & + & + & - \\
\hline $15 A 0107$ & + & - & + & Har/Ser & $P L$ & - & + & + & + \\
\hline
\end{tabular}

Cox Coxiella burnetii, Cab Chlamydia abortus, Lep pathogenic Leptospira spp., MAT Microscopic Agglutination Test, PL placenta, AC abomasal content, mod-ZN Stamp's modification of the Ziehl-Neelsen stain, ChI Chlamydiales, NA not available, +: positive result, -: negative result, $S$ suspect positive, Har Hardjo, Sej Sejroe, Aus Australis, Bal Ballum, Bra Bratislava, Aut Autumnalis, Gri Grippotyphosa, Ict Icterohaemorrhagiae, Pom Pomona, Tar Tarassovi. The serovars are in descending order regarding the titer

and Lubsen [40]. However, previous studies reported similar seropositivity for C. burnetii antibodies but in healthy cows and in different European countries (Bulgaria 20.8\%; France 15\%; Germany 19.3\% and the Netherlands 21\%) [41] suggesting serological results are not reliable for diagnostic purposes. With $38.4 \%$ positive and $13.0 \%$ suspect positive reactions the seropositivity to anti-C. abortus antibodies was the highest of the three abortifacient pathogens investigated in this study. This result was in agreement with studies in other countries which also reported a high prevalence of anti-chlamydial antibodies in cattle, with seropositivity ranging from $45 \%$ to $100 \%$ [42]. However, such high seropositivity rates have to be interpreted with caution. Firstly, a single seropositive result is not necessarily related to the etiology of the abortion and might be due to a previous exposure [43]. Secondly, serological tests may not be $C$. abortus specific and positive titers can arise from crossreactivity to $C$. pecorum, a common intestinal opportunistic chlamydial species found in ruminants [44]. The frequency of Leptospira spp. antibodies was $21.4 \%$ and primarily due to serovar Hardjo (seroprevalence of 17.0\%). The implication of a positive titer to serovar Hardjo on fetal loss remains controversial as many studies failed to show a causal association between seropositivity and abortion [22, 45-48], while others described Hardjo as a cause of abortions $[49,50]$. The interpretation of the serological results for Leptospira spp. should be done carefully since there is cross-reactivity between serovars of the same serogroup; nevertheless, the infecting serovar is more likely to show the higher titer [22, 51]. Although Sejroe was the second most prevalent serovar (14 cases), 12 cases were positive for serovars Hardjo and Sejroe, belonging to the same serogroup. Yet, Hardjo presented the higher titer in 10 cases making Australis (six cases) the second most frequent serovar. Abortion in cattle due to serovar Hardjo is a chronic event with a variable serological response at the time of abortion [22] and confirmation of infection by MAT is difficult because maternal antibody production mostly occurs prior to fetal death [52].

Molecular detection of DNA of abortifacient agents has been shown to be highly sensitive and specific [37, 53-55]. By real-time PCR we detected C. burnetii in $12.1 \%$ of cases, similar to findings in Italy (11.3\%) obtained by nested PCR [56] but lower than results by classical PCR from Portugal (17.2\%) [57] and by real-time PCR from Hungary (25.9\%) [58]. These findings, although obtained with different techniques, may reflect different endemicity. Furthermore, we showed the capacity of $C$. burnetii of spreading via the amniotic-oral route $[59,60]$ with the $7 / 57$ samples of abomasal content being positive. Of the 21 real-time PCR positive cases of C. burnetii, 15 were seronegative suggesting early stages of infection when antibodies are not yet present, or environmental contamination of samples or failure of the dam to seroconvert occurred. In contrast, 23 cases with positive sera were negative by real-time PCR suggesting previous exposure to $C$. burnetii is not uncommon. The statistical analysis showed a poor agreement $(\kappa=0.103 \pm 0.086)$ between the serological and the molecular technique indicating that there is a poor relationship between the seropositivity of the dam for antibodies to C. burnetii and an abortion event as reported previously [61-64]. It is important to keep in mind that real-time PCR is highly sensitive and thus able to detect low levels of $C$. burnetii. Yet, different strains harbor a very variable number of the target IS1111 (between 7 and 110) making quantification inaccurate for this bacterium [65]. For the final interpretation at herd-level it is recommended to include complementary techniques and consider the case history $[18,66]$.

Of 43 real-time PCR-positive samples for Chlamydiales (placenta, $n=41$; abomasal content, $n=2$ ) C. abortus could be identified by sequencing in $9.6 \%$ of the cases, although the prevalence could be higher because in 12 samples a single species could not be assigned due to 
Table 4 Histological lesions in placentas from Coxiella burnetii, Chlamydiales and Leptospira spp. positive cases by real-time PCR

\begin{tabular}{|c|c|c|c|c|c|c|c|}
\hline Sample ID & Placentitis & Necrosis & Type of infiltrate & Vasculitis & Presence of ICB ${ }^{a}$ & Presence of ECB ${ }^{b}$ & $\mathrm{IHC}$ \\
\hline \multicolumn{8}{|c|}{ pos C. burnetii $(n=13)$} \\
\hline 12Ue0622 & Moderate & Moderate & Mixed & Yes & Yes & No & Neg \\
\hline 13Ue0536 & Moderate & Mild & Mixed & No & No & No & Neg \\
\hline 13Ue0858 & Mild & Moderate & Mixed & No & Yes & No & $\mathrm{Neg}$ \\
\hline 13Ue1008 & Moderate & Moderate & Mixed & Yes & No & No & Neg \\
\hline 13Ue1009 & Moderate & Moderate & Mixed & Yes & No & No & Neg \\
\hline 13Ue1414 & Mild & Mild & Neutrophilic & No & Yes & Yes & Neg \\
\hline 13Ue1488 & Mild & Moderate & Neutrophilic & No & Yes & Yes & Neg \\
\hline 13Ue1524 & Mild & Mild & Mixed & Yes & Yes & Yes & Neg \\
\hline 13Ue1644 & No & No & No & No & No & No & Neg \\
\hline $14 \mathrm{~A} 0076$ & Mild & No & Neutrophilic & No & No & Yes & Neg \\
\hline 15A0086 & Mild & Moderate & Mixed & No & Yes & Yes & Neg \\
\hline 15A0101 & Moderate & Moderate & Mixed & No & No & Yes & Neg \\
\hline 15A0107 & Severe & Severe & Mixed & Yes & Yes & No & Neg \\
\hline \multicolumn{8}{|c|}{ pos Chlamydiales $(n=14)$} \\
\hline 12Ue0622 & Moderate & Moderate & Mixed & Yes & Yes & No & $\mathrm{Neg}$ \\
\hline 12Ue1503 & Mild & Mild & Mixed & No & No & Yes & Neg \\
\hline 13Ue1009 & Moderate & Moderate & Mixed & Yes & No & No & Neg \\
\hline $15 A 0076$ & Moderate & Moderate & Mixed & Yes & Yes & Yes & Neg \\
\hline $15 A 0078$ & Severe & Moderate & Mixed & No & No & Yes & $\mathrm{Neg}$ \\
\hline $15 A 0080$ & Moderate & Moderate & Mixed & No & No & Yes & Neg \\
\hline $15 A 0082$ & Severe & Mild & Mixed & No & No & Yes & Neg \\
\hline $15 A 0093$ & Mild & Moderate & Mixed & No & No & Yes & Neg \\
\hline 15A0104 & Moderate & Mild & Mixed & Yes & No & Yes & Neg \\
\hline 15A0107 & Severe & Severe & Mixed & Yes & Yes & No & $\mathrm{Neg}$ \\
\hline $15 \mathrm{~A} 0121$ & Mild & Mild & Mononuclear & No & No & Yes & Neg \\
\hline $15 \mathrm{~A} 0122$ & Mild & Moderate & Neutrophilic & No & No & Yes & Neg \\
\hline $15 \mathrm{~A} 0137$ & Severe & Moderate & Mixed & Yes & Yes & Yes & Neg \\
\hline $15 \mathrm{~A} 0148$ & Moderate & Moderate & Mixed & Yes & No & Yes & Neg \\
\hline \multicolumn{8}{|c|}{ pos Leptospira spp. $(n=5)$} \\
\hline 12Ue1016 & Severe & Mild & Mixed & No & No & Yes & Neg \\
\hline 12Ue1185 & Severe & Mild & Mixed & No & Yes & Yes & $\mathrm{Neg}$ \\
\hline $15 A 0011$ & Mild & Mild & Mononuclear & No & No & Yes & Neg \\
\hline 15A0107 & Severe & Severe & Mixed & Yes & Yes & No & $\mathrm{Neg}$ \\
\hline $15 A 0127$ & Mild & Mild & Mononuclear & No & No & Yes & $\mathrm{Neg}$ \\
\hline
\end{tabular}

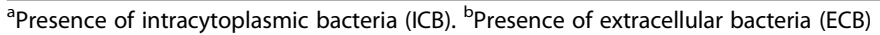

multiple peaks. In Eastern Switzerland, C. abortus was considered not to play an important role in bovine abortion in studies by end-point PCR [39] and real-time PCR [67]. However, Blumer et al. [9] confirmed the presence of C. abortus in $14.8 \%$ of studied cases of abortion from Eastern Switzerland. We could detect members of the Parachlamydiaceae family in four samples confirming that Chlamydia-related bacteria could be involved in bovine abortion as reported previously $[9,39,67]$ and could cause mixed infection [68]. It is noteworthy that some samples with Chlamydia-related bacteria, including $P$. acanthamoebae, were positive by $C$. abortus ELISA also. This result might be due to the production of antibodies that could cross-react with other chlamydialspecies due to a genus-specific epitope of the lipopolysaccharide [44, 69-71]. This might also be the underlying reason for the poor agreement $(\kappa=-0.006 \pm 0.067)$ between the serological and the molecular technique. 


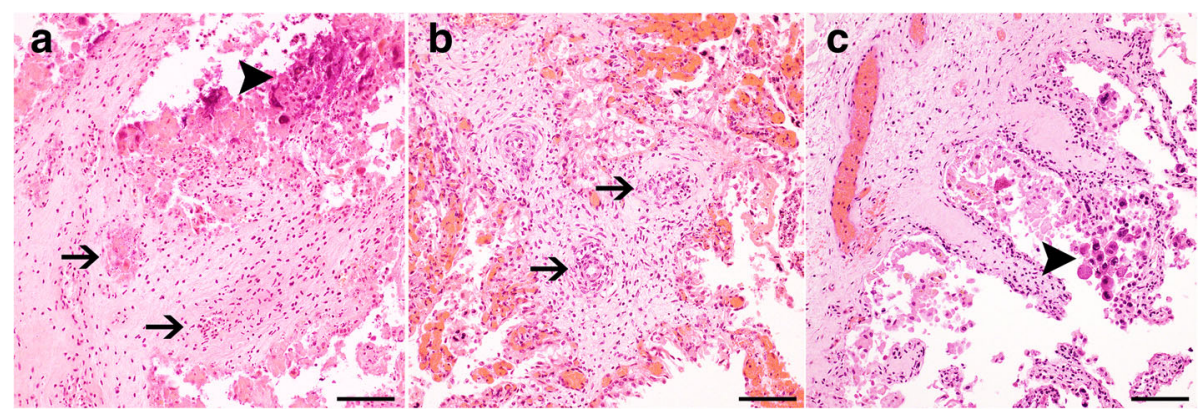

Fig. 3 Histopathology of representative placental samples from bovine abortions positive by real-time PCR for: Coxiella burnetii (a), Chlamydia abortus (b) and pathogenic Leptospira spp. (c). Infection with either C. burnetii (a) or C. abortus (b) was characterized by variable degrees of vasculitis (arrow) and necrosis (arrowhead). Cases positive for pathogenic Leptospira spp. by real-time PCR (c) showed variable severities of necrosis (arrowhead) and lacked vasculitis. HE, bar $100 \mu \mathrm{m}$

In six cases of coxiellosis we found evidence of coinfection with C. abortus and Chlamydiales-related bacteria. Although C. burnetii and Chlamydiales belong to phylogenetically unrelated species [72], they have some similarities in their interaction with the host and mechanisms of pathogenicity [73]. Thus, the diagnosis of either agent is usually established by microscopic examination of stained placenta smears in veterinary diagnostic laboratories but this cannot discriminate between the different organisms. Pritchard et al. [74] stated that the mod-ZN stain is insufficiently sensitive in cattle cotyledons. Our findings agree with this and confirm that the mod-ZN stain is not very sensitive for the detection of either C. burnetii or Chlamydiales infection in bovine abortion material and that it should be replaced by specific real-time PCRs.

Pathogenic Leptospira spp. had a prevalence of 5.6\% by real-time PCR (placenta, $n=14$; abomasal content, $n=1)$. The detection of leptospires in internal organs of aborted or stillborn fetuses reflects chronic leptospirosis of the mother and indicates an active infection of the fetus, but PCR-based diagnosis of leptospirosis alone cannot identify the infecting serovar; moreover, contamination with faeces or autolysis in clinical samples is known to lead to false-negative results [22]. Hence, the combination of both, molecular and serological techniques is of epidemiological value, even though no satisfactory agreement between techniques $(\kappa=0.163 \pm 0.074)$ was achieved. Unfortunately, in only seven cases material was available for both analysis, and four sera of these were positive for serovar Hardjo and one for serovar Icterohaemorrhagiae. Two of the samples positive by real-time PCR for Leptospira spp. DNA were negative in MAT indicating an early stage of the infection or failure to detect seroconversion. In one case, pathogenic Leptospira spp., presumably identified as serovar Hardjo by serology, were detected together with C. burnetii and Chlamydiales and in another case we found possible coinfection between pathogenic Leptospira spp. and C. abortus.

Histological investigation and confirmation of the cellular inflammatory process indicative of infectious agents is important to unambiguously confirm the implication of a specific etiological agent especially if it could also be present in the commensal and the environmental microbiota [43]. However, as the cotyledonary lesions are not pathognomonic for any of the three pathogens investigated [39, 75], a definitive diagnosis based on histopathology only is not possible. Accordingly, in real-time PCR-positive cases of C. burnetii and Chlamydiales we found similar placental lesions varying only in the degree and severity of the inflammatory infiltrate. Although, vasculitis in the placenta of abortion cases is described as a prominent feature of C. abortus infections [39], it is not invariably present. Furthermore, vasculitis in the placenta is present frequently in cases of C. burnetii abortion $[75,76]$ as was observed in this study.

Table 5 Cohen's kappa ( $\mathrm{k}$ ) coefficient with 95\% of Cls to assess the degree of agreement between molecular and serological techniques for the diagnosis of C. burnetii, C. abortus and Leptospira spp.

\begin{tabular}{|c|c|c|c|}
\hline & C. burnetii & C. abortus & Leptospira spp. \\
\hline Number of observed agreements & 145 (79.67\% of the observations) & 103 (56.59\% of the observations) & 146 (80.22\% of the observations) \\
\hline Number of agreements expected by chance & 140.7 (77.33\% of the observations) & 103.5 (56.85\% of the observations) & 139.0 (6.37\% of the observations) \\
\hline Kappa (k) & $0.103 \pm 0.086$ & $-0.006 \pm 0.067$ & $0.163 \pm 0.074$ \\
\hline $95 \% \mathrm{Cls}$ & -0.065 to 0.272 & -0.137 to 0.126 & 0.018 to 0.308 \\
\hline Strength of agreement & Poor & Poor & Poor \\
\hline
\end{tabular}


Additionally, we found that not all Chlamydiales real-time PCR-positive cases displayed vasculitis, similar to previous reports [9, 39]. All Leptospira spp. real-time PCR-positive cases showed necrotizing placentitis with three and two displaying mixed and mononuclear inflammatory infiltrates, respectively. Vasculitis was not observed in any sample except one case which was real-time PCR-positive for C. burnetii and Chlamydiales also. Placental lesions caused by Leptospira spp. in bovine abortion are not well characterized but, based on our limited observations, vasculitis is not a prominent feature.

Lesion-associated pathogen detection is usually considered vital for definitive diagnosis to prove causality. However, we were not able to identify lesion-associated $C$. burnetii, Chlamydiales or Leptospira spp. by IHC in any of the analyzed slides. IHC is known to have lower sensitivity than real-time PCR [77, 78], especially when there is some degree of autolysis in the samples as is often the case for abortion material.

Limited first-line diagnostics (mod-ZN staining) could only detect possible abortifacient agents in 11 cases (4.4\%) while real-time PCR detected a possible abortifacient agent in 78 cases (31.2\%). The fact that (i) C. burnetii, Chlamydiales and Leptospira spp. are all difficult to culture, (ii) serology cannot exclude a past infection or confirm an ongoing infection and (iii) IHC apparently fails to demonstrate the presence of the agents, makes the molecular approach the method of choice.

\section{Conclusions}

In conclusion, we recommend an extended workflow including molecular analysis for routine abortion diagnostics to avoid the underestimation of the discussed agents and histological analysis to avoid misinterpretation of realtime PCR positive results. It would be prudent to use molecular methods initially and then subject positive cases to histological screening. For further epidemiological investigations complementary serological analyses should be considered. However, the real value of this work was determining the inherent public health risk with respect to these zoonotic pathogens and their prevalence in bovine abortion material as important source of infection.

\section{Additional files}

Additional file 1: Table S1. The 12 Leptospira spp. strains used as live antigens in the Microscopic Agglutination test (MAT) obtained from the Royal Tropical Institute (KIT), Amsterdam (The Netherlands). (DOCX 14 kb)

Additional file 2: Table S2. Results of the 249 cases of bovine abortion analyzed in this study. Cox: Coxiella burnetii; Cab: Chlamydia abortus; Lep; pathogenic Leptospira spp.; MAT: Microscopic Agglutination Test; PL: placenta; AC: Abomasal content; mod-ZN: Stamp's modification of the Ziehl-Neelsen stain; Chl: Chlamydiales; Ct: threshold cycle value; NA: not available, +: positive result, -: negative result, S: suspect positive, Har: Hardjo, Sej: Sejroe, Aus: Australis, Bal: Ballum, Bra: Bratislava, Aut:
Autumnalis, Gri: Grippotyphosa, Ict: Icterohaemorrhagiae, Pom: Pomona Tar: Tarassovi. The serovars are in descending order regarding the titer. (DOCX $126 \mathrm{~kb})$

\section{Acknowledgements}

The authors would like to thank Dr. Jarlath Nally (Infectious Bacterial Diseases Research Unit, National Animal Disease Center, Agricultural Research Service, United States Department of Agriculture, Ames, lowa, USA) for kindly providing the LipL32-antibody and are grateful to Valentine Jaquier, Isabelle Brodard and Stefanie Müller for technical assistance.

\section{Funding}

This study was financed by project 1.14 .07 of the Swiss Federal Food Safety and Veterinary Office. Additional funding was obtained from the Institute of Veterinary Bacteriology, University of Bern and from the Scottish Government Rural and Environment Science and Analytical Services Division (RESAS).

\section{Availability of data and materials}

The datasets generated and analyzed during the current study are not publicly available. However, the data can be available from Authors upon request.

\section{Authors' contributions}

SRC and VP conceived the study. SV and SRC were responsible for the study coordination and the data and sample collection. SV and SRC were responsible for the serological analyses and the real-time PCR of C. burnetii and Leptospira spp. SA and GG were responsible for the real-time PCR and sequencing of samples for Chlamydiales. KK and HP were responsible for pathological and histological investigation and immunohistochemistry for Leptospira spp. NB was responsible for immunohistochemistry of Chlamydiaceae. MPD was responsible for immunohistochemistry of C. burnetii. SV drafted the manuscript. SRC and MPD edited the manuscript. All of the authors read and approved the final manuscript.

\section{Ethics approval and consent to participate}

All samples included in this study were received as routine diagnostic submissions for the screening of abortions as prescribed by law.

Consent for publication

Not applicable.

\section{Competing interests}

The authors declare that they have no competing interests.

\section{Publisher's Note}

Springer Nature remains neutral with regard to jurisdictional claims in published maps and institutional affiliations.

\section{Author details}

${ }^{1}$ Institute of Veterinary Bacteriology, Vetsuisse Faculty, University of Bern, Laenggassstrasse 122, CH-3012 Bern, Switzerland. ${ }^{2}$ Graduate School for Cellular and Biomedical Sciences, Theodor Kocher Institute, University of Bern, Freiestrasse 1, CH-3001 Bern, Switzerland. ${ }^{3}$ Institute of Animal Pathology, Vetsuisse Faculty, University of Bern, Laenggassstrasse 122, $\mathrm{CH}-3012$ Bern, Switzerland. ${ }^{4}$ Institute of Microbiology, University Hospital Center and University of Lausanne, Bugnon 48, CH-1011 Lausanne, Switzerland. ${ }^{5}$ Institute of Veterinary Pathology, Vetsuisse Faculty, University of Zurich, Winterthurerstrasse 270, CH - 8057 Zurich, Switzerland. ${ }^{6}$ Moredun Research Institute, Pentlands Science Park, Bush Loan, Penicuik, Edinburgh, Scotland EH26 OPZ, UK.

Received: 28 March 2017 Accepted: 21 November 2017 Published online: 02 December 2017

\section{References}

1. Hässig M, Eggenberger $E$, Künzle $S$, Rüsch P. Reassessment of the herd consultation in facilities with accumulated abortions in cattle. Schweiz Arch Tierheilkd. 2000;142(2):55-64.

2. Rodolakis A, Salinas J, Papp J. Recent advances on ovine chlamydial abortion. Vet Res. 1998;29(3-4):275-88. 
3. Maurin M, Raoult D. Q fever. Clin Microbiol Rev. 1999;12(4):518-53.

4. McDaniel CJ, Cardwell DM, Moeller RB, Jr., Gray GC. Humans and cattle: a review of bovine zoonoses. Vector Borne Zoonotic Dis. 2014;14(1):1-19.

5. Longbottom D, Coulter LJ. Animal chlamydioses and zoonotic implications. J Comp Pathol. 2003;128(4):217-44.

6. Pospischil A, Thoma R, Hilbe M, Grest P, Gebbers JO. Abortion in woman caused by caprine Chlamydophila abortus (Chlamydia psittaci serovar 1). Swiss Med Wkly. 2002;132(5-6):64-6.

7. Borel N, Ruhl S, Casson N, Kaiser C, Pospischil A, Greub G. Parachlamydia spp. and related Chlamydia-like organisms and bovine abortion. Emerg Infect Dis. 2007;13(12):1904-7.

8. Baud D, Goy G, Gerber S, Vial Y, Hohlfeld P, Greub G. Evidence of maternalfetal transmission of Parachlamydia acanthamoebae. Emerg Infect Dis. 2009; 15(1):120-1.

9. Blumer S, Greub G, Waldvogel A, Hässig M, Thoma R, Tschuor A, Pospischil A, Borel N. Waddlia, Parachlamydia and Chlamydiaceace in bovine abortion. Vet Microbiol. 2011;152(3-4):385-93.

10. Lamoth F, Pillonel T, Greub G. Waddlia: an emerging pathogen and a model organism to study the biology of chlamydiae. Microbes Infect. 2015;17(1112):732-7

11. Wheelhouse N, Flockhart A, Aitchison K, Livingstone M, Finlayson J, Flachon V, Sellal E, Dagleish MP, Longbottom D. Experimental challenge of pregnant cattle with the putative abortifacient Waddlia chondrophila. Sci Rep. 2016;6:37150.

12. Willeberg P, Ruppanner R, Behymer DE, Haghighi S, Kaneko JJ, Franti CE. Environmental exposure to Coxiella burnetii: a sero-epidemiologic survey among domestic animals. Am J Epidemiol. 1980;111(4):437-43.

13. Marrie TJ, Schlech WF 3rd, Williams JC, Yates LQ. Fever pneumonia associated with exposure to wild rabbits. Lancet. 1986;1 (8478):427-9.

14. Webster JP, Lloyd G, Macdonald DWQ. Fever (Coxiella burnetii) reservoir in wild brown rats (Rattus norvegicus) populations in the UK. Parasitology. 1995;110(1):31-5.

15. Dunbar MR, Cunningham MW, Roof JC. Seroprevalence of selected disease agents from free-ranging black bears in Florida. J Wildl Dis. 1998;34(3):612-9.

16. Komiya T, Sadamasu K, Kang Ml, Tsuboshima S, Fukushi H, Hirai K. Seroprevalence of Coxiella burnetii infections among cats in different living environments. J Vet Med Sci. 2003;65(9):1047-8.

17. Parker NR, Barralet JH, Bell AMQ. fever. Lancet. 2006;367(9511):679-88.

18. World Organization for Animal Health (OIE). Manual of diagnostic tests and vaccines for terrestrial animals (mammals, birds and bees). 2015;2.1.16.

19. Baud D, Greub G. Intracellular bacteria and adverse pregnancy outcomes. Clin Microbiol Infect. 2011;17(9):1312-22.

20. Raoult D, Chronic Q. Fever: expert opinion versus literature analysis and consensus. J Inf Secur. 2012;65(2):102-8.

21. Bellini C, Magouras I, Chapuis-Taillard C, Clerc O, Masserey E, Peduto G, Péter O, Schaerrer S, Schuepbach G, Greub GQ. Fever outbreak in the terraced vineyards of Lavaux, Switzerland. New Microbes New Infect. 2014;2(4):93-9.

22. World Organization for Animal Health (OIE). Manual of diagnostic tests and vaccines for terrestrial animals (mammals, birds and bees). 2014;2.1.12

23. Cerqueira GM, Picardeau MA. Century of Leptospira strain typing. Infect Genet Evol. 2009;9(5):760-8.

24. Levett PN. Leptospirosis. Clin Microbiol Rev. 2001;14(2):296-326.

25. Adler B, de la Peña-Moctezuma A. Leptospira and leptospirosis. Vet Microbiol 2010;140(3-4):287-296.

26. Dreyfus A, Heuer C, Wilson P, Collins-Emerson J, Baker MG, Benschop J. Risk of infection and associated influenza-like disease among abattoir workers due to two Leptospira species. Epidemiol Infect. 2015;143(10):2095-105.

27. Schreiber PW, Aceto L, Korach R, Marreros N, Ryser-Degiorgis MP, Günthard HF. Cluster of leptospirosis acquired through river surfing in Switzerland. Open Forum Infect Dis. 2015;2(3):ofv102.

28. Pijnacker R, Goris MG, te Wierik MJ, Broens EM, van der Giessen JW, de Rosa M, Wagenaar JA, Hartskeerl RA, Notermans DW, Maassen K, Schimmer B. Marked increase in leptospirosis infections in humans and dogs in the Netherlands, 2014. Euro Surveill. 2016;21(17)

29. Bharti AR, Nally JE, Ricaldi JN, Matthias MA, Diaz MM, Lovett MA, Levett PN, Gilman RH, Willig MR, Gotuzzo E, Vinetz JM. Peru-United States leptospirosis consortium. Leptospirosis: a zoonotic disease of global importance. Lancet Infect Dis. 2003;3(12):757-71.

30. Lau CL, Smythe LD, Craig SB, Weinstein P. Climate change, flooding, urbanization and leptospirosis: fuelling the fire? Trans R Soc Trop Med Hyg 2010;104:631-8.
31. Coghlan JD, Bain AD. Leptospirosis in human pregnancy followed by death of the foetus. Br Med J. 1969;1(5638):228-30.

32. Carles G, Montoya E, Joly F, Peneau C. Leptospirosis and pregnancy. Eleven cases in French Guyana. J Gynecol Obstet Biol Reprod (Paris). 1995;24(4):418-21.

33. Reitt K, Hilbe M, Voegtlin A, Corboz L, Hässig M, Pospischil A. Aetiology of bovine abortion in Switzerland from 1986 to 1995 - a retrospective study with emphasis on detection of Neospora caninum and Toxoplasma gondii by PCR. J Vet Med A Physiol Pathol Clin Med. 2007;54(1):15-22.

34. Stamp JT, McEwen AD, Watt JA, Nisbet DI. Enzootic abortion in ewes; transmission of the disease. Vet Rec. 1950;62(17):251-4.

35. Abril C, Thomann A, Brodard I, Wu N, Ryser-Degiorgis MP, Frey J, Overesch GA. Novel isolation method of Brucella species and molecular tracking of Brucella suis biovar 2 in domestic and wild animals. Vet Microbiol. 2011; 150(3-4):405-10.

36. Howe GB, Loveless BM, Norwood D, Craw P, Waag D, England M, Lowe JR, Courtney BC, Pitt ML, Kulesh DA, Real-time PCR. For the early detection and quantification of Coxiella burnetii as an alternative to the murine bioassay. Mol Cell Probes. 2009;23(3-4):127-31.

37. Lienard J, Croxatto A, Aeby S, Jaton K, Posfay-Barbe K, Gervaix A, Greub G. Development of a new Chlamydiales-Specific Real-time PCR and its application to respiratory clinical samples. J Clin Microbiol. 2011;49(7):2637-42.

38. Villumsen S, Pedersen R, Borre MB, Ahrens P, Jensen JS, Krogfelt KA. Novel TaqMan $^{\circledR}$ PCR for detection of Leptospira species in urine and blood: pit-falls of in silico validation. J Microbiol Methods. 2012;91(1):184-90.

39. Borel N, Thoma R, Spaeni P, Weilenmann R, Teankum K, Brugnera $E_{\text {, }}$ Zimmermann DR, Vaughan L, Pospischil A. Chlamydia-related abortions in cattle from Graubunden, Switzerland. Vet Pathol. 2006:43(5):702-8.

40. Hässig M, Lubsen J. Relationship between abortions and seroprevalences to selected infectious agents in dairy cows. J Veterinary Med Ser B. 1998;45(7):435-41.

41. Georgiev M, Afonso A, Neubauer $H$, Needham $H$, Thiéry $R$, Rodolakis A, Roest HJ, Stärk D, Stegeman JA, Vellema P, van der Hoek W, More SJ. Q fever in humans and farm animals in four European countries, 1982 to 2010. Euro Surveill. 2013;18(8):pii=20407.

42. Kauffold J, Wehrend A, Sigmarsson H, Matthias H. Chlamydia and Chlamydophilia in bovine reproduction. Clin Theriogenol. 2014;6(3):251-4.

43. Borel N, Frey CF, Gottstein B, Hilbe M, Pospischil A, Franzoso FD, Waldvogel A. Laboratory diagnosis of ruminant abortion in Europe. Vet J. 2014;200(2):218-29.

44. Wilson K, Livingstone M, Longbottom D. Comparative evaluation of eight serological assays for diagnosing Chlamydophila abortus infection in sheep. Vet Microbiol. 2009;135(1-2):38-45.

45. Carter ME, Cordes DO, Holland JT, Lewis SF, Lake DE. Leptospirosis: II. Investigation of clinical disease in dairy cattle in the Waikato district of New Zealand. N Z Vet J. 1982;30(9):136-40

46. Dixon RJ. Leptospira interrogans serovar Hardjo: an abortifacient in New Zealand? A review of the literature. N Z Ve J. 1983;31:107-9.

47. Elder JK, McKeon GM, Duncalfe F, Ward WH, Leutton RD. Epidemiological studies on the ecology of Leptospira interrogans serovars pomona and hardjo in Queensland. Prev Vet Med. 1986:3(6):501-21.

48. Chappel RJ, Millar BD, Adler B, Hill J, Jeffers MJ, Jones RT, McCaughan CJ, Mead LJ, Skilbeck NW. Leptospira interrogans serovar hardjo is not a major cause of bovine abortion in Victoria. Aust Vet J. 1989; 66(10):330-3.

49. Ellis WA, Michna SW. Bovine leptospirosis: experimental infection of pregnant heifers with a strain belonging to the Hebdomadis serogroup. Res Vet Sci. 1977;22(2):229-36.

50. Ellis WA, Logan EF, O'Brien JJ, Neill SD, Ferguson HW, Hanna J. Antibodies to Leptospira in the sera of aborted bovine fetuses. Vet Rec. 1978;103(11):237-9.

51. Goris MG, Hartskeerl RA. Leptospirosis serodiagnosis by the microscopic agglutination test. Curr Protoc Microbiol. 2014;6:32

52. Rusbridge S, Caldow G, Crawshaw M, Gunn G. Leptospira hardjo infection in cattle. In: Edinburgh: SAC. Technical note TN 500; 2004. https://www.sruc.ac. uk/download/downloads/id/762/tn500_leptospira_hardjo_infection_in cattle.pdf. Accessed 28 Mar 2017.

53. Laroucau C, Souriau A, Rodolakis A. Improved sensitivity of PCR for Chlamydophila using pmp genes. Vet Microbiol. 2001;82(2):155-64.

54. DeGraves FJ, Gao D, Hehnen HR, Schlapp T, Kaltenboeck B. Quantitative detection of Chlamydia psittaci and C. pecorum by high-sensitivity real-time 
PCR reveals high prevalence of vaginal infection in cattle. J Clin Microbiol. 2003:41(4):1726-9.

55. Berri M, Rekiki A, Boumedine KS, Rodolakis A. Simultaneous differential detection of Chlamydophila abortus, Chlamydophila pecorum and Coxiella burnetii from aborted ruminant's clinical samples using multiplex PCR. BMC Microbiol. 2009;9:130.

56. Parisi A, Fraccalvieri R, Cafiero M, Miccolupo A, Padalino I, Montagna C, Capuano F, Sottili R. Diagnosis of Coxiella burnetii-related abortion in Italian domestic ruminants using single-tube nested PCR. Vet Microbiol. 2006; 118(1-2):101-6.

57. Clemente L, Barahona MJ, Andrade MF, Botelho A. Diagnosis by PCR of Coxiella burnetii in aborted foetuses of domestic ruminants in Portugal. Vet Rec. 2009;164(12):373-4.

58. Kreizinger Z, Szeredi L, Bacsadi A, Nemes C, Sugár L, Varga T, Sulyok KM, Szigeti A, Ács K, Tóbiás E, Borel N, Gyuranecz M. Occurrence of Coxiella burnetii and Chlamydiales species in abortions of domestic ruminants and in wild ruminants in Hungary, Central Europe. J Vet Diagn Investig. 2015;27(2):206-10.

59. Cantas H, Muwonge A, Sareyyupoglu B, Yardimci H, Skjerve EQ. Fever abortions in ruminants and associated on-farm risk factors in northern Cyprus. BMC Vet Res. 2011;7(1):13

60. Agerholm JS. Coxiella burnetii associated reproductive disorders in domestic animals-a critical review. Acta Vet Scand. 2013;55:13.

61. Berri M, Souriau A, Crosby M, Rodolakis A. Shedding of Coxiella burnetii in ewes in two pregnancies following an episode of Coxiella abortion in a sheep flock. Vet Microbiol. 2002;85(1):55-60.

62. Berri M, Rousset E, Champion JL, Russo P, Rodolakis A. Goats may experience reproductive failures and shed Coxiella burnetii at two successive parturitions after a Q fever infection. Res Vet Sci. 2007:83(1):47-52.

63. Rousset E, Berri M, Durand B, Dufour P, Prigent M, Delcroix T, Touratier A, Rodolakis A. Coxiella burnetii shedding routes and antibody response after outbreaks of $\mathrm{Q}$ fever-induced abortion in dairy goat herds. Appl Environ Microbiol. 2009;75(2):428-33.

64. Ruiz-Fons F, Astobiza I, Barandika JF, Hurtado A, Atxaerandio R, Juste RA, García-Pérez AL. Seroepidemiological study of Q fever in domestic ruminants in semi-extensive grazing systems. BMC Vet Res. 2010;6(1):3.

65. Klee SR, Tyczka J, Ellerbrok H, Franz T, Linke S, Baljer G, Appel B. Highly sensitive real-time PCR for specific detection and quantification of Coxiella burnetii. BMC Microbiol. 2006;2006:6,2

66. Sidi-boumedine K, Duquesne V, Rousset E, Cochonneau D, Cutler S J Frangoulidis D, Rodolakis A, Roest HJ, Ruuls R, Van Rotterdam B, Vincent G, Thiéry R. A multicentre MLVA and MST typingring trial for C. burnetii genotyping: An approach to standardisation of methods. 5th MedVetNet Annual Scientific Conference. Madrid, Spain, 2009.

67. Ruhl S, Casson N, Kaiser C, Thoma R, Pospischil A, Greub G, Borel N. Evidence for Parachlamydia in bovine abortion. Vet Microbiol. 2009; 135(1-2):169-74.

68. Borel N, Kempf E, Hotzel H, Schubert E, Torgerson P, Slickers P, Ehricht $R$ Tasara T, Pospischil A, Sachse K. Direct identification of chlamydiae from clinical samples using a DNA microarray assay - a validation study. Mol Cell Probes. 2008;22(1):55-64

69. Casson N, Entenza JM, Greub G. Serological cross-reactivity between different Chlamydia-like organisms. J Clin Microbiol. 2007:45(1):234-6.

70. Borel N, Casson N, Entenza JM, Kaiser C, Pospischil A, Greub G. Tissue microarray and immunohistochemistry as tools for evaluation of antibodies against Chlamydia-like bacteria. J Med Microbiol. 2009;58(Pt7):863-6.

71. Frikha-Gargouri O, Gdoura R, Znazen A, Gargouri J, Rebai A, Hammami A. Diagnostic value of an enzyme-linked immunosorbent assay using the recombinant CT694 species-specific protein of Chlamydia trachomatis. J Appl Microbiol. 2009;107(6):1875-82.

72. Woese CR. Bacterial evolution. Microbiol Rev. 1987:51(2):221-71.

73. Lukáčová M. Are Coxiella burnetii and chlamydiae related? Antigenic properties of Coxiella burnetii and chlamydiae. Alpe Adria Microbiol J. 1996;5:3-13.

74. Pritchard GC, Smith RP, Errington J, Hannon S, Jones RM, Mearns R. Prevalence of Coxiella burnetii in livestock abortion material using PCR. Vet Rec. 2011;169(15):391.

75. Hansen MS, Rodolakis A, Cochonneau D, Agger JF, Christoffersen AB, Jensen TK, Agerholm JS. Coxiella burnetii associated placental lesions and infection level in parturient cows. Vet J. 2011:190(2):e135-9.
76. Bildfell RJ, Thomson GW, Haines DM, McEwen BJ, Smart N. Coxiella burnetii infection is associated with placentitis in cases of bovine abortion. J Vet Diagn Investig. 2000;12(5):419-25.

77. van Maanen C, Wouda W, Schares G, von Blumröder D, Conraths FJ, Norton R, Williams DJ, Esteban-Redondo I, Innes EA, Mattsson JG, Björkman C, Fernández-García A, Ortega-Mora LM, Müller N, Sager H, Hemphill A. An interlaboratory comparison of immunohistochemistry and PCR methods for detection of Neospora caninumin bovine fetal tissues. Vet Parasitol. 2004; 126(4):351-64.

78. Muskens J, Wouda W, von Bannisseht-Wijsmuller T, van Maanen C. Prevalence of Coxiella burnetii infections in aborted foetuses and stillborn calves. Vet Rec 2012;170(10):260.

\section{Submit your next manuscript to BioMed Central and we will help you at every step:}

- We accept pre-submission inquiries

- Our selector tool helps you to find the most relevant journal

- We provide round the clock customer support

- Convenient online submission

- Thorough peer review

- Inclusion in PubMed and all major indexing services

- Maximum visibility for your research

Submit your manuscript at www.biomedcentral.com/submit
Biomed Central 